\title{
Editorial
}

\section{Guest Editorial for Journal of Perinatology Supplement on the Gadchiroli Field Trial}

\section{Robert L. Parker, MD, MPH}

Journal of Perinatology (2005) 25, S1-S2. doi:10.1038/sj.jp.7211279

Neonatal health in developing countries has only recently emerged as a public health priority. In the 1980s and 1990s, the "Child Survival Revolution" focused on interventions that showed the greatest potential to reduce mortality and morbidity among children under 5 years of age. The implementation of several child survival programs - including childhood immunizations, antibiotics to treat pneumonia, oral rehydration fluids to control diarrheal disease,and nutrition monitoring and intervention led to steady decreases in child mortality in many countries. Since parallel improvements in neonatal survival were small, many in the public health community then believed that neonatal interventions could only be effective in countries with better and easily accessible health care facilities. Thus, as under-five mortality decreased overall, neonatal deaths made up an increasing share of under-five mortality.

It wasn't until after the year 2000 that the potential for significantly reducing neonatal mortality in resource-poor areas of the world through the use of simple approaches for recognizing, preventing, and treating neonatal problems at the community level became increasingly apparent. This was due in large part to the publication of a study in 1999 by Dr. Abhay Bang and colleagues in Gadchiroli, India at SEARCH (the Society for Education, Action, and Research in Community Health), which demonstrated a $62 \%$ decline in neonatal mortality rate in rural communities using a "home-based neonatal care" approach. ${ }^{1}$ In 2001, another publication based on the same study described the burden of morbidity among neonates in this rural setting and estimated their unmet need for health care in the preintervention period. ${ }^{2}$ The interventions that worked so well in these remote villages with limited access to formal health care included training local women as village health workers to provide antenatal education visits, to assist traditional midwives at delivery by assuming care of the newborn, and to follow-up the mother and newborn with visits during the neonatal period. The

Senior Research Advisor, SNL, Save the Children, USA; and Adjunct Associate Professor, International Health; The Johns Hopkins University Bloomberg School of Public Health, USA. village health workers were also trained in how to manage birth asphyxia and low birth weight neonates at home, and how to recognize and treat neonatal sepsis. Along with these low-cost technical interventions, the approach succeeded because of the less tangible but equally important long-term relationship of the study team with the communities in solving their health-care problems.

Since the publication of the original study, SEARCH continues to implement and monitor neonatal interventions in the study site. The study team has worked in 39 intervention villages and 47 control villages for more than a decade, effectively turning the community into a neonatology "laboratory," and providing a longer horizon to judge the effectiveness of the home-based neonatal care approach. The project also provides population-based information not previously available on neonates born in homes and critical insights into why the interventions work. Finally, they provide useful guidance to investigators, program managers and policy makers in how to implement essential newborn care at the community level.

Long-term community-based studies provide a rare opportunity to study the health of populations and to develop new health care interventions. Dr. Bang and his colleagues had the foresight to establish such a community-based study site, making the findings reported on in this supplement possible.

The studies in the following pages cover an intriguing range of issues. The authors provide a detailed background of the study setting, including the methods of data collection, the home-based interventions introduced, and the baseline situation to introduce readers unfamiliar with the originally published papers. They then present new analyses and data available from the study site since 1999, including important information on the cause of death among neonates in the study site and their relationship to underlying morbidities; how various combinations of morbidity affect the risk of death as a guide to intervention strategies; new details on the effectiveness of homebased treatment of neonatal sepsis and other neonatal problems; comparisons of different approaches to neonatal resuscitation in home deliveries; management of low birth weight and preterm neonates in the home; and the long-term impact of the interventions in the study site. A summary provides a quick overview of the supplement, conclusions drawn from the findings, and implications for providing care of the newborn in other resource-poor settings. 
The hope of significantly reducing neonatal deaths in developing countries has spurred new research efforts, advocacy and development of new health programs that integrate neonatal interventions into existing maternal and child health care programs - both in homes and within health care systems. It is hoped that the studies published in this supplement will help accelerate more effective newborn care throughout the developing world.

\section{References}

1. Bang AT, Bang RA, Baitule SB, Reddy MH, Deshmukh MD. Effect of homebased neonatal care and management of sepsis on neonatal mortality: field trial in rural India. Lancet 1999;354:1955-61.

2. Bang AT, Bang RA, Baitule SB, Deshmukh MD, Reddy MH. Burden of morbidities and the unmet need for health care in rural neonates - a prospective observational study in Gadchiroli, India. Indian Pediatrics 2001;38:952-64. 